\title{
Rice bran as source of nutraceuticals for management of cardiovascular diseases, cardio-renal syndrome and hepatic cancer
}

\author{
Sahar Y. Al-Okbi ${ }^{*}$, Doha A. Mohamed ${ }^{\circledR}$, Thanaa E. Hamed ${ }^{\circledR}$, Enas S.K. Al-Siedy ${ }^{\circledR}$ \\ Nutrition and Food Sciences Department, National Research Centre, Cairo, Egypt
}

\section{A R T I C L E I N F O}

Article Type:

Original Article

\section{Article History:}

Received: 15 August 2019

Accepted: 4 November 2019

\section{Keywords:}

$\gamma$-Oryzanol

Rice bran oil

Cardiovascular disease

Renal dysfunction

Cardiorenal syndrome

Hepatocellular carcinoma

\begin{abstract}
A B S T R A C T
Introduction: The interrelation between cardiovascular diseases (CVDs) and renal dysfunction and the beneficial role of nutraceuticals are worthy to be studied. Nutraceuticals with anticancer effects are gaining great importance. The aim of this research was studying the anti-cancer, CVDs prevention and renal dysfunction properties of $\gamma$-oryzanol $(\gamma-\mathrm{O})$ and rice bran oil $/ \gamma-\mathrm{O}$ mixture $(\mathrm{RBO} / \gamma-\mathrm{O})$ as nutraceuticals.

Methods: Rats were divided into 7 groups. Group 1 was fed on balanced diet and served as normal control (NC). Group 2 consumed high-fat-sucrose diet (HFSD) as CVD control. Groups 3 and 4 were fed on HFSD and treated by $\gamma-\mathrm{O}$ and $\mathrm{RBO} / \gamma-\mathrm{O}$, respectively. Group 5 was maintained on HFSD with cisplatin injection (cardiorenal syndrome control) (CRSC). Groups 6 and 7 were treated like group 5 and given either $\gamma$-O or $\mathrm{RBO} / \gamma$-O. Plasma lipid profile, malondialdehyde (MDA), tumor necrosis factor- $\alpha$ (TNF- $\alpha$ ), catalase activity, creatinine and urea were determined besides urinary creatinine clearance. Nutraceuticals' anticancer effect was assessed in hepatocellular carcinoma cell (HepG2) line.

Results: Significant increases $(P<0.05)$ in lipid parameters with reduction of high-density lipoprotein cholesterol (HDL-C) were noticed in CVD control compared to NC group; the same changes were demonstrated in CRSC with lesser extent. In CVD control and CRSC groups; significant increase $(P<0.05)$ in MDA and TNF- $\alpha$ with reduction in catalase were noticed. Kidney dysfunction was demonstrated in CRSC group. Administration of both $\mathrm{RBO} / \gamma-\mathrm{O}$ and $\gamma$-O produced variable improvements in all parameters in both models and had anticancer effects. Conclusion: $\mathrm{RBO} / \gamma-\mathrm{O}$ and $\gamma$-O had protective effects on CVDs and cardiorenal syndrome as well as anti-hepatocellular carcinoma activities with superiority of $\mathrm{RBO} / \gamma-\mathrm{O}$.
\end{abstract}

Implication for health policy/practice/research/medical education:

This study revealed that both $\gamma$-oryzanol and $\gamma$-oryzanol/rice bran oil mixture could afford protection from CVDs and cardio-renal syndrome and suppression of hepatic carcinoma with superiority to $\gamma$-oryzanol/rice bran oil mixture. Therefore, consumption of $\gamma$-oryzanol/rice bran oil might be beneficial as preventive remedy for these diseases.

Please cite this paper as: Al-Okbi SY, Mohamed DA, Hamed TE, Al-Siedy ESK. Rice bran as source of nutraceuticals for management of cardiovascular diseases, cardio-renal syndrome and hepatic cancer. J Herbmed Pharmacol. 2020;9(1):68-74. doi: 10.15171/jhp.2020.10.

\section{Introduction}

Dyslipidemia translated in hypertriglyceridemia, hypercholesterolemia, elevated low-density lipoproteincholesterol (LDL-C) and reduced high-density lipoprotein-cholesterol (HDL-C) along with elevated total cholesterol//HDL-C has been reported as predictor of cardiovascular diseases (CVDs). This is because such sustained dyslipidemia induces high oxidative stress and proinflammatory condition that all together can lead to CVDs (1). Disturbed life style, due to high intake of saturated fat and high consumption of sugar especially sucrose and fructose together with lack of physical activity, might produce the aforementioned dyslipidemia, oxidative stress and inflammation. Renal dysfunction might be initiated as a result of CVD (2). On the other hand, kidney dysfunction might exacerbate CVDs in dyslipidemic subjects (3). Cardiorenal syndrome (CRS) term reflects the co-existence of renal and CVDs which 
can lead to adverse outcomes (4). It is hypothesized that nutraceuticals with reported antioxidant, antiinflammatory and lipid lowering effects might attenuate the incidence of both CVDs and renal dysfunction. It is also assumed that survival of cancer cells might be inhibited by anti-inflammatory natural agents thereby reducing progression and metastasis of cancer. Rice bran oil (RBO) is a rich source of nutraceuticals represented by gamma oryzanol, policosanol, phytosterols, carotenoids, tocopherols and tocotrienols that have different health benefits including anti-inflammatory, antioxidant and hepatoprotective effects. Gamma oryzanol is a mixture of ferulic acid esters of triterpene alcohol of reported different therapeutic effects $(5,6)$. The objective of the present work was to study the protective effects of nutraceuticals represented by $\gamma$-oryzanol $(\gamma-\mathrm{O})$ and $\gamma-\mathrm{O} /$ RBO mixture towards CVD and cardio-renal syndrome in rat. The aim also included studying the reduction in survival of liver carcinoma cell line on application of the aforementioned nutraceuticals.

\section{Materials and Methods}

Preparation of rice bran oil

Egyptian rice bran was stabilized directly after milling by heating at $125^{\circ} \mathrm{C}$ for 15 minutes, ground, sieved through 40 mesh sieve, packed in polyethylene bags and kept at $-30^{\circ} \mathrm{C}$ until used (7). Stabilized rice bran was subjected to continuous extraction by Soxhlet apparatus using petroleum ether $\left(40-60^{\circ} \mathrm{C}\right)$ for oil extraction. The solvent was completely removed by evaporation under reduced pressure at a temperature not exceeding $40^{\circ} \mathrm{C}$. RBO was kept in deepfreeze until used.

Gamma oryzanol

Gamma oryzanol was obtained from International laboratory (IL), USA.

\section{Anticancer activity}

Liver human tumor derived cell line (HepG2) was supplied from National Cancer Institute, Cairo University, Egypt. Anticancer activity of nutraceuticals represented by $\mathrm{RBO} / \gamma-\mathrm{O}$ mixture $(6: 1)$ and $\gamma-\mathrm{O}$ alone was tested using the cell line technique as previous (8). Cells of HepG2 (liver carcinoma cell) were plated in 96-multiwell plate $\left(10^{4}\right.$ cells/well $)$ for 24 hours before treatment to be attached to the wall of plate. $\mathrm{RBO} / \gamma-\mathrm{O}$ mixture and $\gamma$-O were dissolved separately in dimethyl sulfoxide at $10 \mathrm{mM}$ as a stock solution. Different concentrations of the nutraceuticals $(0,5,12.5,25$ and $50 \mu \mathrm{g} / \mathrm{mL})$ were added to the cell monolayer; triplicate wells were prepared for each individual dose of each nutraceutical. The plates were incubated for 48 hours at $37^{\circ} \mathrm{C}$ in an atmosphere of $5 \% \mathrm{CO}_{2}$. After 48 hours, the cells were fixed, washed and stained with sulforhodamine-B stain, then excess stain was washed with acetic acid and attached stain was recovered with Tris EDTA buffer. Color intensity was measured in an ELISA reader. The relation between surviving fraction of cancer cell and nutraceuticals doses was plotted. The concentration of nutraceuticals which reduced survival of the exposed cancer cells to $50 \%\left(\mathrm{IC}_{50}\right)$ was obtained from the curves.

\section{Animal experiment}

\section{Preparation of nutraceuticals' dosage form}

$\mathrm{RBO}$ and $\gamma-\mathrm{O}$ were mixed together (6:1) for preparation of a mixture to be given as daily oral dose to rats by gastric tube. The mixture was emulsified in water using gum acacia. Gamma-oryzanol alone was also made into emulsion by gum acacia. For the control groups of rats, the vehicle was prepared through dissolving the same amount of gum acacia in water.

\section{Design of experimental procedure}

Male albino rats weighing 130-155 g were obtained from animal house of National Research Centre, Cairo, Egypt. Animals were kept individually in stainless steel cages; metabolic cages were used for housing rats that were subjected to urine collection. Water and food were given ad libitum with $12 \mathrm{~h}$ light/dark cycle. Experimental diets were prepared as in Table 1. High-fat-sucrose diet (HFSD) which was devoid from fibers was used to promote CVD in rats (through dyslipidemia, oxidative stress and inflammation). Cisplatin (Platinol, $1 \mathrm{mg} / \mathrm{mL}$ ), purchased from Mayne Pharmaceuticals (Warwickshire, UK) was used for induction of renal dysfunction. The applied dose was $7.5 \mathrm{mg} / \mathrm{kg}$ rat body weight as intraperitoneal one dose which was reported to induce nephrotoxicity in rats (9).

Forty-two male rats were divided into seven equal groups. Rats of group one represented the normal control (NC) and fed on balanced diet. Rats of group 2 were fed on HFSD and served as CVD control. Rats of group 3 and 4 were fed on HFSD and given daily oral dose of RBO/ $\gamma$-O mixture $(300 \mathrm{mg} \mathrm{RBO}$ and $50 \mathrm{mg} \gamma$-O/kg rat body weight) and $50 \mathrm{mg} \gamma$-O/kg rat body weight, respectively. Rats of group 5 were fed on HFSD and treated by intraperitoneal cisplatin on the day 31 which stand for cardiorenal syndrome control (CRSC). Rats of groups

Table 1. Composition of thel diets (g per $100 \mathrm{~g}$ ) used in this experiment

\begin{tabular}{lcc}
\hline Ingredients & Balanced diet & HFSD diet \\
\hline Casein & 12 & 12 \\
Corn oil & 10 & - \\
Sheep tallow & - & 26 \\
Sucrose & - & 38.0 \\
Starch & 70.5 & 19.5 \\
Salt mix. & 3.5 & 3.5 \\
Vitamin mix. & 1 & 1 \\
Cellulose & 3 & - \\
\hline
\end{tabular}

HFSD: High saturated fat- high sucrose diet

$12 \mathrm{~g}$ casein has been estimated to contain $10 \mathrm{~g}$ protein. 
6 and 7 were given daily oral dose of $\mathrm{RBO} / \gamma$-O mixture (300 $\mathrm{mg} \mathrm{RBO}$ and $50 \mathrm{mg} \gamma-\mathrm{O} / \mathrm{kg}$ rat body weight) and $50 \mathrm{mg} \gamma-\mathrm{O} / \mathrm{kg}$, respectively and were fed on HFSD with intraperitoneal injection of cisplatin on the day 31 . Rats of the three control groups (1, 2 \& 5) were given daily oral dose of equal amounts of the vehicle received by the test groups. The experimental period lasted 35 days. During the experiment, rats' body weight and food intake were recorded weekly. At the end of the experiment, 24 hour urine was collected from all rats treated with cisplatin for determination of urinary creatinine (10). Blood samples were collected from anesthetized rats of all groups after an overnight fast. Plasma samples were separated and used for biochemical analysis. Plasma malondialdehyde (MDA) was assessed as indicator of lipid peroxidation according to previous procedure (11). Plasma catalase activity, an antioxidant biomarker, and tumor necrosis factor- $\alpha$ (TNF- $\alpha$ ), an inflammatory biomarker, were determined as previously mentioned $(12,13)$. Plasma creatinine and urea were estimated $(10,14)$ as representative of kidney function. The activities of aspartate transaminase (AST) and alanine transaminase (ALT) were determined as indicators of liver function (15). Lipid profile represented by plasma total cholesterol (TC), HDL-C, LDL-C and triglycerides (TG) were assessed by colorimetric methods (16-19). The ratio of TC/HDL-C was calculated as predictor of CVDs. Creatinine clearance $(\mathrm{mL} / \mathrm{min})$ was calculated as determinant of glomerular filtration rate [Urinary creatinine $(\mathrm{mg} / \mathrm{dL}) \times 24 \mathrm{~h}$ urine $(\mathrm{mL}) /$ plasma creatinine $(\mathrm{mg} / \mathrm{dL}) \times 1440]$. Both kidneys and liver were immediately excised and weighed for calculation of organ/ body weight $\%$. Total food intake, body weight gain and food efficiency ratio (body weight gain/total food intake) were calculated.

\section{Statistical analysis}

The results of animal experiments were expressed as the mean \pm standard error (SE) and analyzed statistically using the one-way analysis of variance ANOVA followed by Tukey test.

\section{Results}

The anticancer effect of $\mathrm{RBO} / \gamma$-O mixture and $\gamma$-O against HepG 2 cells is shown in Figure $1 . \mathrm{RBO} / \gamma$-O mixture was more efficient than $\gamma$-O where $\mathrm{IC}_{50}$ was $37 \mu \mathrm{g}$ and $39.5 \mu \mathrm{g} /$ $\mathrm{mL}$, respectively.

The results of plasma parameters of different experimental groups are illustrated in Table 2. Plasma levels of TC, TG, LDL-C and the ratio of TC/HDL-C showed significant increase in association with significant reduction in plasma levels of HDL-C in HFSD control with or without cisplatin injection compared to NC. The rats fed on HFSD and treated by $\mathrm{RBO} / \gamma-\mathrm{O}$ mixture or $\gamma$-O alone showed significant improvement in plasma lipid profile with superiority to $\mathrm{RBO} / \gamma-\mathrm{O}$ mixture.

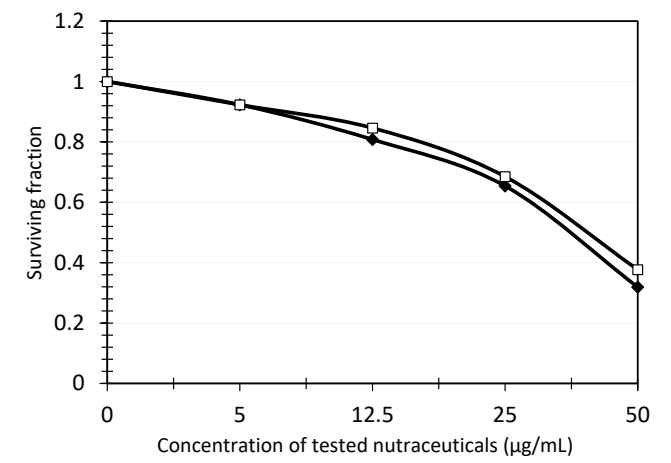

$\multimap$ Rice bran oil and gamma-oryzanol mixture

$\neg-$ Gamma-oryzanol

Figure 1. Anticancer effect of rice bran oil/gamma-oryzanol mixture and gamma-oryzanol against HepG2 cells.

Administration of $\mathrm{RBO} / \gamma$-O mixture or $\gamma$-O alone to rats fed on HFSD with cisplatin injection showed significant improvement in plasma LDL-C, HDL-C and TC/HDL-C compared to their corresponding control; while TG was only improved on treatment with the $\mathrm{RBO} / \gamma-\mathrm{O}$ mixture, meanwhile no improvement was noticed in $\mathrm{T}-\mathrm{C}$ on both treatments. Again $\mathrm{RBO} / \gamma-\mathrm{O}$ mixture was more efficient in improving plasma lipid profile in HFSD/cisplatin model.

Plasma levels of MDA and TNF- $\alpha$ showed significant elevation in HFSD and HFSD/cisplatin control compared to NC. Plasma catalase activity demonstrated significant reduction in both diseases models compared to NC. HFSD/cisplatin model produced severe elevation in MDA and TNF- $\alpha$ and reduction of catalase activity compared to HFSD model. Oral administration of $\mathrm{RBO} / \gamma-\mathrm{O}$ mixture or $\gamma$-O alone showed significant reduction in MDA and TNF- $\alpha$ in association with significant elevation of the activity of catalase; $\mathrm{RBO} / \gamma$-O mixture was more promising in both rat models.

Plasma activities of transaminases (AST and ALT) showed significant elevation in both HFSD control and HFSD/cisplatin control, while kidney function parameters (creatinine and urea) demonstrated significant increase only in HFSD/cisplatin control. Administration of $\mathrm{RBO} / \gamma-\mathrm{O}$ mixture or $\gamma-\mathrm{O}$ alone significantly improved liver function in both rat models. Both treatments reduced plasma levels of creatinine and urea in HFSD/ cisplatin model. In this respect; $\mathrm{RBO} / \gamma-\mathrm{O}$ mixture was more efficient than $\gamma$-O in the two tested rat models in improving renal and hepatic function.

Table 3 shows urinary data and creatinine clearance of different experimental groups. Treatment of HFSD fed rats with cisplatin for induction of kidney dysfunction demonstrated significant elevation of urine volume when compared with normal rats. Urinary creatinine and creatinine clearance significantly reduced in HFSD/ cisplatin control compared to NC. Oral administration of $\mathrm{RBO} / \gamma$-O mixture or $\gamma$-O alone significantly reduced urine volume, with significant elevation of urinary creatinine 
Table 2. Plasma lipid profile, MDA, TNF-a, catalase activity and liver and kidney function of different experimental groups

\begin{tabular}{|c|c|c|c|c|c|c|c|}
\hline & NC & HFSD control & $\begin{array}{c}\text { HFSD + RBO/ } \\
\gamma-\mathrm{O}\end{array}$ & HFSD $+\nu-O$ & $\begin{array}{c}\text { HFSD \& Cisplatin } \\
\text { control }\end{array}$ & $\begin{array}{c}\text { HFSD \& } \\
\text { Cisplatin+ RBO/ } \\
\text { V-O }\end{array}$ & $\begin{array}{c}\text { HFSD \& } \\
\text { Cisplatin+ }+-O\end{array}$ \\
\hline $\mathrm{T}-\mathrm{C}(\mathrm{mg} / \mathrm{dL})$ & $87.18^{\mathrm{a}} \pm 1.59$ & $125.67^{d} \pm 2.56$ & $105.5^{b} \pm 2.13$ & $113.17^{c} \pm 3.23$ & $108.33^{b c} \pm 2.81$ & $102.83^{b} \pm 1.35$ & $108.33^{b c} \pm 2.3$ \\
\hline $\mathrm{TG}(\mathrm{mg} / \mathrm{dL})$ & $91.72^{\mathrm{a}} \pm 1.15$ & $112.67^{d} \pm 3.84$ & $95.00^{\mathrm{ab}} \pm 1.46$ & $98.00^{\mathrm{abc}} \pm 1.46$ & $103.5^{c} \pm 2.28$ & $94.5^{a b} \pm 2.16$ & $98.67^{b c} \pm 1.2$ \\
\hline $\mathrm{HDL}-\mathrm{C}(\mathrm{mg} / \mathrm{dL})$ & $43.50^{\mathrm{e}} \pm 0.62$ & $25.17^{\mathrm{a}} \pm 0.7$ & $35.33^{d} \pm 0.49$ & $32.00^{c} \pm 0.58$ & $25.67^{\mathrm{a}} \pm 0.76$ & $35.5^{d} \pm 0.5$ & $30.00^{b} \pm 0.77$ \\
\hline LDL-C (mg/dL) & $21.5^{\mathrm{a}} \pm 0.89$ & $101.67^{d} \pm 2.97$ & $72.33^{b} \pm 1.11$ & $76.33^{\mathrm{bc}} \pm 1.09$ & $99.83^{d} \pm 2.12$ & $72.83^{b} \pm 2.12$ & $79.17^{c} \pm 1.54$ \\
\hline $\mathrm{T}-\mathrm{C} / \mathrm{HDL}-\mathrm{C}$ & $2.01^{\mathrm{a}} \pm 0.06$ & $5.00^{e} \pm 0.11$ & $2.99^{b} \pm 0.07$ & $3.54^{c} \pm 0.13$ & $4.25^{d} \pm 0.22$ & $2.9^{b} \pm 0.06$ & $3.61^{\mathrm{c}} \pm 0.03$ \\
\hline $\operatorname{MDA}(\mathrm{nmol} / \mathrm{mL})$ & $9.02^{\mathrm{a}} \pm 0.34$ & $19.75^{d} \pm 0.38$ & $13.85^{\mathrm{b}} \pm 0.32$ & $16.00^{c} \pm 0.58$ & $23.67^{\mathrm{e}} \pm 0.71$ & $15.17^{b c} \pm 0.48$ & $20.5^{d} \pm 0.76$ \\
\hline TNF- $\alpha(\mathrm{pg} / \mathrm{mL})$ & $20.2^{a} \pm 0.59$ & $35.33^{e} \pm 0.71$ & $26.67^{b} \pm 0.88$ & $31.00^{c d} \pm 0.97$ & $40.00^{f} \pm 1.06$ & $29.83^{c} \pm 0.95$ & $33.33^{\text {de }} \pm 0.88$ \\
\hline Catalase (u/L) & $456.15^{f} \pm 6.00$ & $323.52^{b} \pm 4.72$ & $423.90^{\mathrm{e}} \pm 5.76$ & $406.17^{\mathrm{e}} \pm 5.86$ & $200.18^{\mathrm{a}} \pm 8.61$ & $380.50^{d} \pm 7.41$ & $348.17^{c} \pm 9.78$ \\
\hline Creatinine $(\mathrm{mg} / \mathrm{dL})$ & $0.76^{a} \pm 0.03$ & $0.77^{a} \pm 0.01$ & $0.78^{a} \pm 0.03$ & $0.81^{a} \pm 0.02$ & $3.4^{d} \pm 0.18$ & $1.22^{b} \pm 0.06$ & $1.72^{c} \pm 0.07$ \\
\hline Urea (mg/dL) & $30.1^{\mathrm{a}} \pm 1.45$ & $35.83^{c} \pm 1.3$ & $32.00^{\mathrm{ab}} \pm 0.00$ & $34.00^{b c} \pm 0.00$ & $190.46^{f} \pm 0.00$ & $72.00^{\mathrm{e}} \pm 0.00$ & $65.00^{d} \pm 0.00$ \\
\hline ALT (IU/L) & $42.83^{a} \pm 1.14$ & $70.33^{c} \pm 1.89$ & $61.00^{\mathrm{b}} \pm 1.03$ & $62.83^{b} \pm 1.11$ & $71.17^{c} \pm 1.05$ & $60.50^{b} \pm 0.67$ & $63.50^{\mathrm{b}} \pm 0.99$ \\
\hline AST (IU/L) & $56.50^{\mathrm{a}} \pm 1.36$ & $83.83^{\mathrm{e}} \pm 1.64$ & $69.67^{b} \pm 0.88$ & $74.00^{c d} \pm 0.93$ & $86.17^{\mathrm{e}} \pm 0.87$ & $72.00^{b c} \pm 0.89$ & $76.00^{d} \pm 0.58$ \\
\hline
\end{tabular}

In each row shared superscript letter means non-significant difference while unshared letter means significant difference $(P \leq 0.05)$. The data are expressed as mean values \pm standard error.

NC: Normal control, HFSD: High fat high sucrose diet, RBO: Rice bran oil, $\gamma$-O: $\gamma$-Oryzanol, RBO/ $\gamma$-O: Mixture of RBO and $\gamma$-Oryzanol, HFSD\& Cisplatin: Rats fed on HFSD and injected by intraperitoneal cisplatin.

Table 3. Urinary creatinine, urine volume and creatinine clearance of different experimental groups

\begin{tabular}{lccc}
\hline Groups & Urinary creatinine $(\mathrm{mg} / \mathrm{dL})$ & Urine volume $(\mathrm{mL} / \mathbf{2 4} \mathrm{h})$ & $\mathrm{Creatinine} \mathrm{clearance}(\mathrm{mL} / \mathrm{min})$ \\
\hline Normal control & $14.17^{\mathrm{c}} \pm 0.6$ & $9.17^{\mathrm{a}} \pm 0.48$ & $0.12^{\mathrm{c}} \pm 0.01$ \\
HFSD \& cisplatin control & $8.04^{\mathrm{a}} \pm 0.34$ & $23.67^{\mathrm{c}} \pm 0.88$ & $0.04^{\mathrm{a}} \pm 0.004$ \\
HFSD \& cisplatin+ RBO/ $\mathrm{y}-\mathrm{O}$ & $12.17^{\mathrm{b}} \pm 0.6$ & $14.33^{\mathrm{b}} \pm 0.67$ & $0.1^{\mathrm{c}} \pm 0.01$ \\
HFSD \& cisplatin $+\gamma-\mathrm{O}$ & $10.83^{\mathrm{b}} \pm 0.6$ & $15.67^{\mathrm{b}} \pm 0.67$ & $0.07^{\mathrm{b}} \pm 0.01$ \\
\hline
\end{tabular}

In each column similar superscript letter means non-significant difference while different letter means significant difference $(P \leq 0.05)$. The data are expressed as mean values \pm standard error.

NC: Normal control, HFSD: High fat high sucrose diet, RBO: Rice bran oil, $\nu$-O: $\gamma$-Oryzanol, RBO/ $\gamma$-O: Mixture of RBO and $\gamma$-Oryzanol, HFSD \& Cisplatin: Rats fed on HFSD and injected by intraperitoneal cisplatin.

and creatinine clearance; $\mathrm{RBO} / \gamma-\mathrm{O}$ was superior.

Nutritional parameters, liver/ body weight percent and kidney/body weight percent of different experimental groups are complied in Table 4. Final body weight, body weight gain, total food intake and relative percentage of liver weight/body weight of HFSD control rats showed significant increase compared to NC. Only total food intake and relative percentage liver weight/body weight demonstrated significant increase in HFSD/cisplatin control compared to NC. Kidney/body weight percentage did not show any significant changes among groups. Administration of $\mathrm{RBO} / \gamma-\mathrm{O}$ mixture or $\gamma$-O alone significantly improved nutritional parameters towards normal in both rat models.

\section{Discussion}

The induction of dyslipidemia, high TC/HDL-C, oxidative stress and inflammation by feeding HFSD in the present research, represent risk factors for CVDs. Prevention of such changes could avert progression to CVDs. Mutual interaction between CVDs and renal dysfunction is an important issue that requires intense investigations. CVDs might predispose renal dysfunction and renal dysfunction might lead to CVDs which probably could be related to rennin angiotensin system activity (2); and hence the CRS could exist. It was worthy to study the detrimental effect of dyslipidemia and accompanied inflammation and oxidative stress induced by HFSD on renal function in the current study. Treatment of rats with cisplatin during feeding HFSD was implemented to study to what extent renal dysfunction induced by cisplatin might elevate the risk factors for CVDs. HFSD showed severe dyslipidemia compared to HFSD accompanied by treatment with cisplatin while more rigorous elevated oxidative stress and inflammatory biomarkers were observed in the latter case. This indicated that the metabolism related to inflammation and oxidative stress might be the interrelated core in CRS but not the dyslipidemia. However, considering that 
Table 4. Nutritional parameters (Initial and final body weight, body weight gain, total food intake and food efficiency ratio) and percentage of liver and kidney to body weight of different experimental groups

\begin{tabular}{|c|c|c|c|c|c|c|c|}
\hline Groups & $\begin{array}{l}\text { Initial body } \\
\text { weight } \\
\text { (g) }\end{array}$ & $\begin{array}{l}\text { Final body } \\
\text { weight } \\
\text { (g) }\end{array}$ & $\begin{array}{l}\text { Body weight } \\
\text { gain (g) }\end{array}$ & $\begin{array}{l}\text { Total food } \\
\text { intake (g) }\end{array}$ & $\begin{array}{l}\text { Food efficiency } \\
\text { ratio }\end{array}$ & $\begin{array}{c}\% \text { Liver/Body } \\
\text { weight }\end{array}$ & $\begin{array}{c}\text { \% Kidney/ } \\
\text { Body weight }\end{array}$ \\
\hline NC & $143.3^{\mathrm{a}} \pm 1.15$ & $199.2^{\mathrm{ab}} \pm 1.96$ & $55.8^{\mathrm{ab}} \pm 2.04$ & $487.8^{\mathrm{a}} \pm 3.7$ & $0.11^{\mathrm{a}} \pm 0.004$ & $3.14^{a} \pm 0.08$ & $0.78^{a} \pm 0.03$ \\
\hline HFSD control & $143.2^{\mathrm{a}} \pm 1.2$ & $214.0^{c} \pm 1.81$ & $70.8^{c} \pm 2.37$ & $545.8^{d} \pm 4.73$ & $0.13^{b} \pm 0.004$ & $3.84^{d} \pm 0.04$ & $0.70^{\mathrm{a}} \pm 0.03$ \\
\hline $\mathrm{HFSD}+\mathrm{RBO} / \gamma-\mathrm{O}$ & $143.2^{\mathrm{a}} \pm 1.62$ & $203.8^{\mathrm{ab}} \pm 2.83$ & $60.7^{\mathrm{ab}} \pm 1.48$ & $498.5^{\mathrm{ab}} \pm 5.02$ & $0.12^{\mathrm{ab}} \pm 0.003$ & $3.6^{c} \pm 0.05$ & $0.75^{a} \pm 0.03$ \\
\hline $\mathrm{HFSD}+\gamma-\mathrm{O}$ & $143.5^{\mathrm{a}} \pm 2.66$ & $205.3^{b} \pm 1.45$ & $61.8^{\mathrm{b}} \pm 2.6$ & $505.2^{\mathrm{bc}} \pm 4.87$ & $0.12^{\mathrm{ab}} \pm 0.005$ & $3.63^{c d} \pm 0.08$ & $0.72^{\mathrm{a}} \pm 0.02$ \\
\hline HFSD \& cisplatin control & $143.17^{\mathrm{a}} \pm 3.38$ & $201.3^{\mathrm{ab}} \pm 2.6$ & $58.2^{\mathrm{ab}} \pm 1.4$ & $516.8^{c} \pm 4.4$ & $0.11^{\mathrm{a}} \pm 0.003$ & $3.54^{\mathrm{bc}} \pm 0.07$ & $0.76^{\mathrm{a}} \pm 0.05$ \\
\hline $\mathrm{HFSD} \&$ cisplatin $+\mathrm{RBO} / \mathrm{Y}-\mathrm{O}$ & $143.5^{\mathrm{a}} \pm 3.82$ & $198.0^{\mathrm{a}} \pm 2.32$ & $54.5^{\mathrm{a}} \pm 2.67$ & $491.5^{\mathrm{ab}} \pm 5.3$ & $0.11^{\mathrm{a}} \pm 0.006$ & $3.31^{\mathrm{ab}} \pm 0.08$ & $0.78^{a} \pm 0.02$ \\
\hline HFSD \& cisplatin $+\gamma-O$ & $143.2^{\mathrm{a}} \pm 2.47$ & $199.5^{\mathrm{ab}} \pm 1.52$ & $56.3^{\mathrm{ab}} \pm 1.61$ & $496.8^{\mathrm{ab}} \pm 5.04$ & $0.11^{\mathrm{a}} \pm 0.003$ & $3.15^{\mathrm{a}} \pm 0.12$ & $0.75^{a} \pm 0.03$ \\
\hline
\end{tabular}

In each column shared superscript letter means non-significant difference while unshared letter means significant difference $(P \leq 0.05)$. The data are expressed as mean values \pm standard error.

NC: Normal control, HFSD: High fat high sucrose diet, RBO: Rice bran oil, $\gamma$-O: $\gamma$-Oryzanol, RBO/ $\gamma$-O: Mixture of RBO and $\gamma$-Oryzanol, HFSD\& Cisplatin: Rats fed on HFSD and injected by intraperitoneal cisplatin.

dyslipidemia could induce inflammation and oxidative stress, this make it more sense that cross-talk of lipid metabolism, oxidative stress and inflammation might be integral items in the induction of CRS.

Feeding HFSD produced liver dysfunction without affecting renal function while cisplatin treatment during this diet produced both liver and kidney dysfunction. Liver dysfunction during feeding HFSD might be related to accumulation of liver fat due to the fructose moiety of sucrose that enhances lipid synthesis and inhibits fat degradation through reduction of fatty acids betaoxidation. The saturated fat in HFSD also enhances the deposition of liver fat. Fat accumulation in liver together with the increased TNF- $\alpha$, the inflammatory biomarker, might produce a case of steatohepatitis that leads to liver dysfunction with simultaneous dyslipidemia and risk of CVDs. Dietary fructose and saturated fat are correlated with dyslipidemia, insulin resistance and oxidative stress (20). Treatment with cisplatin certainly produced renal dysfunction as reported previously (9).

High fat high sugar diet was reported to induce obesity, metabolic syndrome, CVDs and kidney diseases with possible progression to CRS on the long run $(21,22)$. The feeding period of HFSD in the present study was only 5 weeks so kidney dysfunction was not observed therefore, cisplatin treatment was important to induce similar changes.

RBO improved insulin sensitivity and up-regulated the expression of hepatic gene of insulin receptors (23) thereby reduced fat accumulation in liver, dyslipidemia, oxidative stress and the incidence of CVDs. RBO containing $\gamma$-O improved lipid profile, anti-oxidant status in hyperlipidemic subjects (24). Gamma-oryzanol was reported to have hypolipidemic and antioxidant activity thereby reduced diabetic nephropathy which was ascribed to down regulation of lipid biosynthesis through inhibiting sterol regulatory element binding protein1-associated transforming growth factor-beta (25). The results in the present study agreed with the aforementioned research where $\gamma$-O improved lipid profile, oxidative stress and kidney function. Gamma-oryzanol improved body weight, hypertriglyceridemia, kidney damage, structural and functional alteration of the heart in rats fed high fathigh sugar diet for 20 weeks (21). Bread supplemented with $\mathrm{RB}$ was shown previously to have reno-protective effect (26). At certain stage of renal failure diuresis occurs due to prostaglandin E2 secretion which inhibits cation reabsorption with consequent polyuria (27), this resembles the polyuria demonstrated in HFSD/cisplatin control. Prostaglandin E2 is an inflammatory biomarker that may be enhanced during renal dysfunction and which might be inhibited on administration of the studied nutraceuticals. Glomerular filtration rate assessed by creatinine clearance was also improved during treatment with $\gamma$-O with or without $\mathrm{RBO}$ indicating reno-protective effect.

Lipid profile (TC, TG, LDL-C and HDL-C) was improved with reduction in body weight and liver weight in mice fed high fat diet and treated with $\gamma-\mathrm{O}(28)$ which agreed with the present work. NF-kB might have important function in lipid lowering by $\gamma$-O. Lipid metabolism related-gene expressions were regulated by $\gamma-\mathrm{O}$ while expression of inflammatory factors was inhibited by $\gamma$-O in liver tissue of mice fed on high fat diet. Liver fat was also reduced by $\gamma$-O and $\mathrm{RBO}(6,28)$ which might have a hand in reduction of body weight and liver weight/body weight percentage observed in the present study.

Tocotrienols, which are one of the rice bran bioactive constituents, were demonstrated to possess cardioprotective, lipid lowering, and anti-inflammatory activities (29). They were also reported to have antineoplastic effects (30); the proposed mechanism was mediated through apoptotic, cell cycle arrest, angiogenesis 
inhibition, metastasis suppression, non-coding RNAs regulation, anti-inflammatory and antioxidant activities. Antiproliferative activity of phytosterol and $\gamma$-O, as bioactive constituents in RBO, was demonstrated previously (31). The above mentioned studies support the anticancer effect of the tested nutraceuticals in the present work.

The presence of carotenoids, policosanol and phytosterols in RBO might participate in the antioxidant, anti-inflammatory, hypolipidemic, renoprotective and cytotoxic effects demonstrated in the present study.

The synergistic effect of $\gamma$-O with the different bioactive constituents of RBO might lead to superiority of $\mathrm{RBO} /$ $\gamma$-O mixture on $\gamma-\mathrm{O}$ alone in improving the CVDs risk factors, liver and kidney function and the observed anti cancer effect.

\section{Conclusion}

Gamma-oryzanol/RBO mixture and $\gamma$-O might be used as cardio- and reno-protective nutraceuticals and could prevent cardio-renal syndrome. In addition, these nutraceuticals possess anti-cancer activity against HepG2.

\section{Acknowledgements}

This work was carried out in Nutrition and Food Sciences Department, National Research Centre (NRC), Egypt.

\section{Authors' contribution}

ASY designed the study and wrote the paper with interpretation of results. MDA prepared first draft of materials and methods with results tabulation. MDA, HTE and AESK participated in implementation of the practical part. AESK analyzed the result statistically. All authors read and approved the final version and agreed to publish it.

\section{Conflict of interests}

None to be declared.

\section{Ethical considerations}

During this study; the animals received humane care according to the Medical Research Ethics Committee, National Research Centre, Cairo, Egypt, and followed the recommendations of the National Institutes of Health Guide for Care and Use of Laboratory Animals (Publication No. 85-23, revised 1985).

\section{Funding/Support}

None.

\section{References}

1. Al-Okbi SY, El-Qousy SM, El-Ghlban S, Moawad HF. Role of Borage Seed Oil and Fish Oil with or without Turmeric and Alpha- Tocopherol in Prevention of Cardiovascular Disease and Fatty Liver in Rats. J Oleo Sci. 2018;67(12):1551-62. doi: 10.5650/jos.ess 18064 .
2. Watanabe R, Suzuki J, Wakayama K, Kumagai H, Ikeda Y, Akazawa $\mathrm{H}$, et al. Angiotensin II receptor blocker irbesartan attenuates cardiac dysfunction induced by myocardial infarction in the presence of renal failure. Hypertens Res. 2016;39(4):237-44. doi: 10.1038/hr.2015.141.

3. Ayodele OE, Alebiosu CO. Burden of chronic kidney disease: an international perspective. Adv Chronic Kidney Dis. 2010;17(3):215-24. doi: 10.1053/j.ackd.2010.02.001.

4. Latini R, Aleksova A, Masson S. Novel biomarkers and therapies in cardiorenal syndrome. Curr Opin Pharmacol. 2016;27:56-61. doi: 10.1016/j.coph.2016.01.010.

5. Al-Okbi SY, Ammar NM, Mohamed DA, Hamed IM, Desoky AH, El Bakry HF, et al. Egyptian rice bran oil: chemical analysis of the main phytochemicals. Riv Ital Sostanze Grasse. 2014;91(1):47-58.

6. Al-Okbi SY, Mohamed DA, Hamed TE, Esmail RSH. Rice bran oil and pumpkin seed oil alleviate oxidative injury and fatty liver in rats fed high fructose diet. Pol J Food Nutr Sci. 2014;64(2):127-33. doi: 10.2478/pjfns-2013-0002.

7. Ammar HO, Al-Okbi SY, Mostafa DM, Helal AM. Rice bran oil: preparation and evaluation of novel liquisolid and semisolid formulations. Int $J$ Pharm Compd. 2012;16(6):516-23.

8. Cordero CP, Morantes SJ, Páez A, Rincón J, Aristizábal FA. Cytotoxicity of withanolides isolated from Acnistus arborescens. Fitoterapia. 2009;80(6):364-8. doi: 10.1016/j. fitote.2009.05.011.

9. Al-Okbi SY, Mohamed DA, Hamed TE, Esmail RSH, Donya SM. Plant food extracts as a source of bioactive compounds for prevention of cisplatin-induced kidney dysfunction in rats. Pol J Food Nutr Sci. 2014;64(1):49-57. doi: 10.2478/ v10222-012-0092-2.

10. Houot O. Interpretation of clinical laboratory tests. California, USA: Biomedical Publications; 1985. p. 220-34.

11. Satoh K. Serum lipid peroxide in cerebrovascular disorders determined by a new colorimetric method. Clin Chim Acta. 1978;90(1):37-43. doi: 10.1016/0009-8981(78)90081-5.

12. Aebi H. Catalase in vitro. Methods Enzymol. 1984;105:1216. doi: 10.1016/s0076-6879(84)05016-3.

13. Stepaniak JA, Gould KE, Sun D, Swanborg RH. A comparative study of experimental autoimmune encephalomyelitis in Lewis and DA rats. J Immunol. 1995;155(5):2762-9.

14. Fawcett JK, Scott JE. A rapid and precise method for the determination of urea. J Clin Pathol. 1960;13:156-9. doi: 10.1136/jcp.13.2.156.

15. Reitman S, Frankel S. A colorimetric method for the determination of serum glutamic oxalacetic and glutamic pyruvic transaminases. Am J Clin Pathol. 1957;28(1):56-63. doi: 10.1093/ajcp/28.1.56.

16. Watson D. A simple method for the determination of serum cholesterol. Clin Chim Acta. 1960;5:637-43. doi: 10.1016/0009-8981(60)90004-8.

17. Burstein M, Scholnick HR, Morfin R. Rapid method for the isolation of lipoproteins from human serum by precipitation with polyanions. J Lipid Res. 1970;11(6):583-95.

18. Schriewer H, Kohnert U, Assmann G. Determination of LDL cholesterol and LDL apolipoprotein B following precipitation of VLDL in blood serum with phosphotungstic acid/MgCl2. J Clin Chem Clin Biochem. 1984;22(1):35-40. 
doi: $10.1515 / \mathrm{cclm} .1984 .22 .1 .35$.

19. Megraw RE, Dunn DE, Biggs HG. Manual and continuousflow colorimetry of triacylglycerols by a fully enzymic method. Clin Chem. 1979;25(2):273-8.

20. Johnson RJ, Segal MS, Sautin Y, Nakagawa T, Feig DI, Kang $\mathrm{DH}$, et al. Potential role of sugar (fructose) in the epidemic of hypertension, obesity and the metabolic syndrome, diabetes, kidney disease, and cardiovascular disease. Am J Clin Nutr. 2007;86(4):899-906. doi: 10.1093/ajcn/86.4.899.

21. Francisqueti FV, Minatel IO, Ferron AJT, Bazan SGZ, Silva VDS, Garcia JL, et al. Effect of gamma-oryzanol as therapeutic agent to prevent cardiorenal metabolic syndrome in animals submitted to high sugar-fat diet. Nutrients. 2017;9(12). doi: 10.3390/nu9121299.

22. Rodríguez-Monforte $\mathrm{M}$, Sánchez $\mathrm{E}$, Barrio $\mathrm{F}$, Costa $\mathrm{B}$, Flores-Mateo G. Metabolic syndrome and dietary patterns: a systematic review and meta-analysis of observational studies. Eur J Nutr. 2017;56(3):925-47. doi: 10.1007/s00394016-1305-y.

23. Mohamed MA, Ahmed MA, Abd Elbast SA, Ali NA. Rice bran oil ameliorates hepatic insulin resistance by improving insulin signaling in fructose fed-rats. J Diabetes Metab Disord. 2019;18(1):89-97. doi: 10.1007/s40200-019-003942.

24. Bumrungpert A, Chongsuwat R, Phosat C, Butacnum A. Rice Bran Oil Containing Gamma-Oryzanol Improves Lipid Profiles and Antioxidant Status in Hyperlipidemic Subjects: A Randomized Double-Blind Controlled Trial. J Altern Complement Med. 2019;25(3):353-8. doi: 10.1089/ acm.2018.0212.
25. Bhaskaragoud G, Geetha V, Sharanappa T, Mohan Kumar AS, Hema Kumar C, Suresh Kumar G. Hypolipidemic and Antioxidant Properties of Oryzanol Concentrate in Reducing Diabetic Nephropathy via SREBP1 Downregulation Rather than beta-Oxidation. Mol Nutr Food Res. 2018;62(8):e1700511. doi: 10.1002/ mnfr.201700511.

26. Al-Okbi SY, Mohamed DA, Hamed TE, Hussein AM. Cereals' products with red grape and walnut extracts as functional foods for prevention of kidney dysfunction. Int J Biol Biomol Agric Food Biotechnol Eng. 2013;7(7):583-9.

27. Natochin Iu V, Bogolepova AE. [Possible mechanisms of polyuria in progressive chronic renal failure]. Ter Arkh. 2000;72(6):15-20.

28. Wang L, Lin Q, Yang T, Liang Y, Nie Y, Luo Y, et al. Oryzanol modifies high fat diet-induced obesity, liver gene expression profile, and inflammation response in mice. J Agric Food Chem. 2017;65(38):8374-85. doi: 10.1021/acs.jafc.7b03230.

29. Medvedev OS, Medvedeva NA. [Biological properties of tocotrienols]. Vopr Pitan. 2018;87(2):5-16. doi: 10.24411/0042-8833-2018-10013.

30. Aggarwal V, Kashyap D, Sak K, Tuli HS, Jain A, Chaudhary A, et al. Molecular mechanisms of action of tocotrienols in cancer: recent trends and advancements. Int J Mol Sci. 2019;20(3). doi: 10.3390/ijms20030656.

31. Lesma G, Luraghi A, Bavaro T, Bortolozzi R, Rainoldi G, Roda G, et al. Phytosterol and gamma-Oryzanol Conjugates: Synthesis and Evaluation of their Antioxidant, Antiproliferative, and Anticholesterol Activities. J Nat Prod. 2018;81(10):2212-21. doi: 10.1021/acs.jnatprod.8b00465 